\title{
Deterioration mechanisms of sludge settleability in sludge reduction systems with metabolic uncouplers
}

\author{
Yunping Han a, b, Meng Luo a, b, Hong Chen ${ }^{c}$, Wenzhe Zhang a, b, Junxin Liu ${ }^{\text {a, b }}$, \\ Benyi Xiao ${ }^{\text {a, b, d, * }}$ \\ a State Key Joint Laboratory of Environmental Simulation and Pollution Control, Research Center for Eco-Environmental Sciences, Chinese Academy of \\ Sciences, Beijing 100085, China \\ ${ }^{\mathrm{b}}$ University of Chinese Academy of Sciences, Beijing 100049, China \\ ' School of Hydraulic Engineering, Changsha University of Science and Technology, Changsha, Hunan 410004, China \\ ${ }^{\mathrm{d}}$ Beijing Key Laboratory of Industrial Wastewater Treatment and Reuse, Research Center for Eco-Environmental Sciences, Chinese Academy of Sciences, \\ Beijing 100085, China
}

\section{A R T I C L E I N F O}

\section{Article history:}

Received 2 June 2017

Received in revised form

31 July 2017

Accepted 31 July 2017

Available online 5 August 2017

\section{Keywords:}

$\mathrm{N}$-acyl-L-homoserine lactone content

Metabolic uncoupler

Deterioration mechanism

Sludge reduction system

Settleability

\begin{abstract}
A B S T R A C T
The deterioration of sludge settleability is a common problem in sludge reduction systems with metabolic uncouplers (MUs). The deterioration mechanisms were studied by conducting laboratory-based tests for 85 days. The sludge volume index $\left(\mathrm{SVI}_{30}\right)$ increased from $88.0 \mathrm{~mL} / \mathrm{g}$ SS to $149.5-158.9 \mathrm{~mL} / \mathrm{g}$ SS with MUs. The addition of MUs decreased the N-acyl-L-homoserine lactone (AHLs) content of the sludge by increasing the AHL-degrading bacteria (Paenibacillus spp., Bacillus spp. and Microbacterium sp.) and decreasing or eliminating the AHL-producing bacteria (Paracoccus sp.). Meanwhile, the addition of MUs increased the extracellular polymeric substances (EPS) of sludge and decreased its proteinpolysaccharide ratio (PN/PS). The decrease of AHL content and the changes of EPS resulted in the deterioration of sludge settleability in the MUs systems. The statistical analysis suggested the decrease of AHL content was more important than the change of sludge EPS on deteriorate the sludge settleability. (c) 2017 Elsevier Ltd. All rights reserved.
\end{abstract}

\section{Introduction}

Activated sludge process is commonly used throughout the world to treat domestic and industrial wastewater. Excess sludge is its primary by-product, which is produced in large amounts and consists of microbial biomass that requires treatment and disposal. Because its treatment and disposal constitutes $50-60 \%$ of total operational costs of wastewater treatment plants (WWTPs) (Campos et al., 2009; Semblante et al., 2015), excess sludge is a large concern for many WWTPs. Many technologies were developed to reduce the production of excess sludge directly in wastewater treatment facilities (Guo et al., 2013). Among these technologies, metabolic uncoupler (MU) addition is a promising method, and has attracted many attentions. This method is convenient, efficient, easy to operate, and is used without modification of conventional wastewater treatment processes or facilities (Guo et al., 2013).

* Corresponding author. State Key Joint Laboratory of Environmental Simulation and Pollution Control, Research Center for Eco-Environmental Sciences, Chinese Academy of Sciences, Beijing 100085, China.

E-mail address: byxiao@rcees.ac.cn (B. Xiao).
Some MUs, like 3,3',4',5-tetrachlorosalicylanilide (TCS) (Ye and Li, 2005; Feng et al., 2014; Li et al., 2016), 2,4-dichlorophenol (DCP) (Xie et al., 2010; Han et al., 2017), and tetrakis (hydroxymethyl) phosphonium sulfate (THPS) (Guo et al., 2014; Li et al., 2016) have been used in previous studies.

Although MUs reduce sludge production, they may also deteriorate sludge settleability (Guo et al., 2013). Previous studies have reported the deterioration of sludge settleability in sludge reduction systems with MUs (Ye and Li, 2005; Guo et al., 2014; Fang et al., 2015). For example, Ye and Li (2005) found $40 \mathrm{mg} / \mathrm{d}$ TCS increased the sludge volume index (SVI) by $15 \%$ in a 15 -L aeration tank, and Fang et al. (2015) found the SVI of sludge increased by 4\%, 25\% and $13 \%$ with the addition of Pcp, Ocp and Onp concentrations in ranges of $5-20 \%$. Although the deterioration of sludge settleability in most studies was slight and usually did not affect (or only insignificantly affected) wastewater treatment efficiency (Ye and Li, 2005; Zheng et al., 2008), some studies reported serious deterioration of sludge settleability, which led to sludge bulking, low wastewater treatment efficiency, and even system breakdown (Zheng et al., 2008; Guo et al., 2014). For example, Guo et al. (2014) found that 
the SVI of activated sludge increased from $217.4 \mathrm{~mL} / \mathrm{g}$ MLSS to 284. $7 \mathrm{~mL} / \mathrm{g}$ MLSS, and some sludge was washed out with the effluent when THPS was added in a pilot-scale anaerobic/anoxic/oxic process $\left(\mathrm{A}^{2} \mathrm{O}\right)$. Zheng et al. (2008) found that $10 \mathrm{mg} / \mathrm{L}$ malonic acid resulted in the breakdown of sequence batch reactors because of sludge bulking.

Without careful and efficient control, even a slight deterioration of sludge settleability may become a serious problem (Sperling, 2007). To effectively control the deterioration of sludge settleability in sludge reduction systems with MUs, it is important to understand its underlying mechanisms. Previous studies had reported several mechanisms such as the presence of large amounts of filaments (Zheng et al., 2008), the disappearance of the protozoa filaments and the protozoa (Zheng et al., 2008), the decrease of sludge floc size (Zheng et al., 2008; Guo et al., 2014), and the increase of extracellular polymeric substances (EPS) (Fang et al., 2015). However, the exact underlying mechanisms have yet to be systematically investigated. Since the deterioration of sludge settleability would affect the application of sludge reduction technology with MUs, it is necessary to study the deterioration mechanisms of sludge settleability in sludge reduction system with MUs in detail.

In activated sludge process, sludge exists as flocs, and activated sludge flocs are composed of a highly dense microbial consortium in a matrix of EPS. Quorum sensing (QS) refers to the phenomenon that planktonic bacterial cells may regulate their collective actions in response to environmental challenges through sensing specific chemical molecules (Waheed et al., 2016; Wu et al., 2017). The QS signaling molecules (like $\mathrm{N}$-acyl-L-homoserine lactone, AHL) mediated gene expression is a cell density-dependent gene expression mechanism, and QS may exist in activated sludge flocs since it is a model high-density microbiological community (Huang et al., 2016). Previous studies have reported the existence of AHLs and AHLs-producing microorganisms in activated sludge flocs (Valle et al., 2004; Chong et al., 2012; Lv et al., 2014; Waheed et al., 2016; Sun et al., 2017). QS in monospecies biofilms was shown to regulate different aspects of biofilm formations, maturation and distribution of EPS (Wu et al., 2017), such as surface colonization by cell motility, biofilm thickness, the formation of bacterial clusters or structurally homogeneous biofilms, and overall biofilm depth and architecture (Solano et al., 2014). The assembly of microorganisms in activated sludge and formation of floc structures may also be regulated by QS signaling molecules, since activated sludge flocs are biofilms without surface association (Chong et al., 2012). As such, the weakness of the floc structure and the microbial assembly in deteriorated activated sludge within sludge reduction systems with MUs may be the result of less QS signaling molecules and weak QS regulation. However, few studies focused on the relationship between the deterioration of activated sludge and QS signaling molecules.

Therefore, to promote the development and application of sludge reduction technology with MUs, the objective of this study was to investigate the deterioration mechanisms of sludge settleability in sludge reduction system with MUs in long term, especially from the standpoint of QS.

\section{Materials and methods}

\subsection{Wastewater and metabolic uncoupers}

The wastewater used in the test came from a residential area in Beijing, China. The characteristics of the wastewater are summarized in Table 1, which were same as previous studies (Li et al., 2016; Han et al., 2017). According to previous study (Li et al., 2016), three MUs, TCS (Acros Organics Co. Ltd, Belgium), DCP
Table 1

Characteristics of wastewater used in the test.

\begin{tabular}{lll}
\hline Parameter & Range & Mean \\
\hline $\mathrm{pH}$ & $7.56-8.43$ & 7.87 \\
$\mathrm{COD}(\mathrm{mg} / \mathrm{L})$ & $64-452$ & 172 \\
$\mathrm{SS}(\mathrm{mg} / \mathrm{L})$ & $16-551$ & 195 \\
$\mathrm{NH}_{4}^{+}-\mathrm{N}(\mathrm{mg} / \mathrm{L})$ & $24.41-59.54$ & 46.11 \\
$\mathrm{TN}(\mathrm{mg} / \mathrm{L})$ & $37.57-92.42$ & 56.93 \\
$\mathrm{TP}(\mathrm{mg} / \mathrm{L})$ & $3.03-9.45$ & 5.86 \\
\hline
\end{tabular}

(Tokyo Chemical Industry Co., Ltd, Japan), and THPS (Solvay Co. Ltd, France), were used in the test.

\subsection{Wastewater treatment systems and their operations}

Four lab-scale anaerobic-anoxic-oxic (A2O) systems were used in the test, which were same as those used in previous studies ( $\mathrm{Li}$ et al., 2016; Han et al., 2017). The design and operation parameters of the four A2O systems are also same as previous studies ( $\mathrm{Li}$ et al., 2016; Han et al., 2017) and the details are as follows: the working volumes for each part of the A2O were $4 \mathrm{~L}$ (anaerobic tanks), $4 \mathrm{~L}$ (anoxic tanks), $16 \mathrm{~L}$ (oxic tanks) and $4 \mathrm{~L}$ (settlement tanks). The anaerobic and anoxic tanks were mixed via mechanical stirring, and the oxic tanks were aerated to maintain the dissolved oxygen (DO) levels. The DO and hydraulic retention times (HRTs) of the former three tanks were $<0.1 \mathrm{mg} / \mathrm{L}$ and $2 \mathrm{~h}$ (anaerobic tanks), $0.2-0.5 \mathrm{mg} / \mathrm{L}$ and $2 \mathrm{~h}$ (anoxic tanks), and $1.5-3.0 \mathrm{mg} / \mathrm{L}$ and $8 \mathrm{~h}$ (oxic tanks), respectively. The HRT in settling tank was $2 \mathrm{~h}$. The internal (namely mixing liquor recycling) and external recycling ratios (namely sludge recycling) were controlled at $100 \%$ and $200 \%$, respectively. The inoculum sludge used in all tanks of test was obtained from the aeration tank of a municipal WWTP in Beijing, China, which uses an activated sludge process and handles 400,000 tons of wastewater daily. The sludge concentrations (mixed liquor suspended solids, MLSS) in the oxic tanks were controlled at $2-4 \mathrm{~g} /$ L by regularly discharging sludge. The sludge retention time (SRT) of control system was about 9.6-10.5 d, while those of MUs systems were about $12.6-13.4 \mathrm{~d}$.

Three of the A2O systems had MUs continuously added to their oxic tanks, and the fourth A2O system was maintained as a control, with no MU added. The three MUs were added, one to each treatment system, at doses of $0.8 \mathrm{mg} / \mathrm{L}$ influent (TCS), $20 \mathrm{mg} / \mathrm{L}$ influent (2,4-DCP), and $3.5 \mathrm{mg} / \mathrm{L}$ influent (THPS), which were selected according to previous studies (Feng et al., 2014; Guo et al., 2014; Li et al., 2016). The influent and effluent of four systems and activated sludge in the oxic tanks were regularly sampled and measured (twice/week). The test was conducted at room temperature $\left(20-28{ }^{\circ} \mathrm{C}\right)$ for 85 days. The SVI was used as the index of sludge settleability. Based on the SVI of activated sludge, the operation of the four systems was divided into two stages: 0-30 and $31-85$ days.

\subsection{Analytical methods}

The water quality parameters of the influent and effluent were analyzed, including the soluble and total chemical oxygen demand (SCOD and TCOD), $\mathrm{NH}_{4}^{+}-\mathrm{N}$, the total nitrogen (TN), total phosphorous (TP), $\mathrm{pH}$, and suspended solids (SS). Characteristics of the activated sludge in the oxic tanks of the four systems were analyzed, including the sludge concentrations (MLSS) and the SVI. The SCOD and TCOD of wastewater were analyzed with a DR2000 COD meter (HACH, Loveland, CO, USA). The samples were filtered through a $0.45-\mu \mathrm{m}$ membrane before determining the SCOD. The $\mathrm{pH}$ was measured with a PB-10 pH meter (Sartorius, Göttingen, 
Germany). The dissolved oxygen (DO) was measured with an online DO meter ( $\mathrm{HACH}$, Loveland, $\mathrm{CO}, \mathrm{USA})$. The $\mathrm{NH}_{4}^{+}-\mathrm{N}$, the total nitrogen (TN), total phosphorous (TP) were measured with spectrophotometry and the SS with weight method according to the standard methods (APHA, 1998). The sludge reduction in the three MUs systems was calculated according to the method of Guo et al. (2014). The EPS of activated sludge samples was extracted using a cation-exchange resin (Dowex Marathon $\mathrm{C}$ ) technique described by Liu and Fang (2002). The protein (PN) content in the EPS was determined by the Lowry method (Lowry et al., 1951) with bovine serum albumin as the standard. The polysaccharide (PS) content in the EPS was determined by the phenol-sulfuric acid method with glucose as the standard (Dubois et al., 1956). The relative AHL content and microbial attachment potential of activated sludge were measured as described by Lv et al. (2014), and the data of microbial attachment potential were collected after $24 \mathrm{~h}$ of incubation. The particle sizes of the activated sludge were measured with a Mastersizer 2000 particle size analyzer (Malvern, UK). Average results and standard errors were reported in triplicate for each analysis or determination.

\subsection{DNA extraction, PCR, DGGE and sequencing}

The activated sludge in the oxic tanks of the four systems were sampled at the stage of sludge settleability deterioration, on the $70^{\text {th }}$ day, and the microbial population of the samples was analyzed using molecular biological methods (DNA extraction, polymerase chain reaction (PCR), denaturing gradient gel electrophoresis (DGGE), and sequencing). The DNA of the sludge samples was extracted by a nucleic acid automatic extraction system (TANBead Smart LabAssist-16, Taiwan). The extracted DNA was then used as the template for PCR amplification and DGGE.

PCR primers 341F (5'-CCTACGGGAGGCAGCAG-3') and 534R ( $5^{\prime}-$ ATTACCGCGGCTGCTGG-3') were used to amplify a segment of the eubacterial 16S rRNA. A GC-clamp was added to the forward primers to facilitate DGGE. PCR amplification was performed using a C1000 thermal cycler (BioRad, Philadelphia, PA, USA) at a final reaction volume of $50 \mu$ l. The reaction mixture contained $1 \mu \mathrm{l}$ of both primers $(10 \mu \mathrm{M}), 4 \mu \mathrm{l}$ of each dNTP, $5 \mu \mathrm{l}$ of $10 \times$ buffer, a 50 -ng DNA template, and 1.5 units of Taq DNA polymerase. Temperature cycling conditions were $95{ }^{\circ} \mathrm{C}$ for $5 \mathrm{~min}$, followed by 30 cycles of $93^{\circ} \mathrm{C}$ for $1 \mathrm{~min}, 48^{\circ} \mathrm{C}$ for $1 \mathrm{~min}$, and $72^{\circ} \mathrm{C}$ for $1 \mathrm{~min}$, and then a final extension at $72{ }^{\circ} \mathrm{C}$ for $10 \mathrm{~min}$. A $5-\mu \mathrm{l}$ aliquot of the PCR product was separated on a $0.8 \%(\mathrm{w} / \mathrm{v})$ agarose gel at $100 \mathrm{~V}$ for $30 \mathrm{~min}$ to verify amplification prior to DGGE. DGGE of the PCR-amplified 16S rDNA was performed using a D-Code system (BioRad, Philadelphia, PA, USA) In addition, 30\%-60\% of the denaturing gradients were used to separate the amplified $16 \mathrm{~S}$ rDNA. The gel was electrophoresed in $1 \times$ TAE buffer at $70 \mathrm{~V}$ and $60^{\circ} \mathrm{C}$ for $10 \mathrm{~h}$. The resulting gel was then visualized using Gel Red (Biotium, Fremont, CA, USA). An analysis of the DGGE gel was conducted using Bio-Rad software, Quantity One $^{\mathrm{TM}}$ (BioRad, Philadelphia, PA, USA).

Prominent DGGE bands were excised and submitted for sequencing with the ABI 3730DXL DNA sequence (Applied Biosystem, Oakwood, OH, USA). The sequences were then compared with those available in the GenBank (NCBI) database by BLASTN.

\subsection{Data analysis}

A statistical analysis was performed to identify the quantitative relationships among the sludge characteristics, and a representative approach of univariate linear correlations was used (Ou et al., 2014) with IBM SPSS Statistics 19.0 software (SPSS, Chicago, IL, USA).

\section{Results and discussion}

\subsection{Sludge reductions, wastewater treatment efficiencies, and sludge settleability}

During the tests, excess sludge reductions, wastewater treatment efficiencies, and the sludge settleability of activated sludge in the oxic tanks were measured, and the results are summarized in Table 2 .

In the first stage (0-30 days), the average SVI of the activated sludge was similar among the four systems and changed in 80.1-83.8 $\mathrm{mL} / \mathrm{g}$ SS (Table 2). In the second stage (31-85 d), the average SVIs of the activated sludge in the four systems all increased. The control system only increased $6.6 \mathrm{~mL} / \mathrm{g} \mathrm{SS}$, while those of the three MUs systems increased $67.1-75.1 \mathrm{~mL} / \mathrm{g}$ SS (Table 2). The settleabilities of the activated sludge in the control system were good in the two stages, whereas those in the three MUs systems changed from good in the first stage to fair in the second stage (Sperling, 2007). The results showed the settleabilities of the activated sludge deteriorated with the addition of the three MUs.

In the two stages, the wastewater treatment efficiencies of the four systems were 85.7-91.1\% (COD), 93.2-98.9\% ( $\left.\mathrm{NH}_{4}^{+}-\mathrm{N}\right)$, $58.8-70.4 \%$ (TN) and $53.7-58.9 \%$ (TP) (Table 2). The removals of COD, TN, TP and $\mathrm{NH}_{4}^{+}-\mathrm{N}$ decreased slightly due to the addition of the MUs, and the decreased removals of TN, TP and $\mathrm{NH}_{4}^{+}-\mathrm{N}$ was slightly higher in the second stage. Compared to the control system, the removals of COD, $\mathrm{NH}_{4}^{+}-\mathrm{N}, \mathrm{TN}$ and TP in the systems with the three MUs decreased by $0.3-9.8 \%$ (Table 2), which were similar to the results of previous studies (Zheng et al., 2008; Guo et al., 2014). When comparing the changes in wastewater treatment efficiencies and sludge settleability of the activated sludge, it could be found that they tracked each other, which suggested the deterioration of sludge settleability may be a factor for decrease of wastewater treatment efficiencies because some sludge washed out with the sewage during the sludge settleability deterioration process (Zheng et al., 2008; Guo et al., 2014).

The excess sludge reductions of the three MUs systems were similar in the two stages, and were $38.6-38.7 \%$ for the TCS system, 43.4-45.4\% for the DCP system and $38.3-39.3 \%$ for the THPS system (Table 2), which were similar to the results of previous studies (Guo et al., 2013; Feng et al., 2014; Li et al., 2016). The results of the excess sludge reductions suggested that the systems with the three MUs in this study were normal.

\subsection{EPS of activated sludge}

The PN and PS (two main components of EPS) contents in the EPS of activated sludge in the second stage (31-85 days) were measured (Fig. 1-A). The PN contents in the EPS of activated sludge changed in the four systems as follows: $12.6-12.9 \mathrm{mg} / \mathrm{g}$ SS (control system), 14.1-15.1 mg/g SS (TCS system), 13.5-14.3 mg/g SS (DCP system), and 13.6-15.3 mg/g SS (THPS system) (Fig. 1-A). The PS contents in the EPS of the activated sludge changed in the four systems as follows: $7.8-8.0 \mathrm{mg} / \mathrm{g} \mathrm{SS}$ (control system), $9.0-9.3 \mathrm{mg} / \mathrm{g}$ SS (TCS system), $8.7-8.9 \mathrm{mg} / \mathrm{g}$ SS (DCP system), and $9.3-9.7 \mathrm{mg} / \mathrm{g}$ SS (THPS system) (Fig. 1-A). The results showed the PN and PS contents of the activated sludge EPS increased with the addition of the three MUs. Because activated sludge EPS is mainly composed by PN and PS (Sheng et al., 2010), the EPS content of activated sludge also increased with the addition of the three MUs. Since these MUs are xenobiotic and toxic to microorganisms (Feng et al., 2014), upon their addition into the wastewater treatment system, sludge microorganisms generate more EPS, a protective barrier of microorganisms, to resist the toxicity of the MUs, survive in the presence of 
Table 2

The sludge reductions, wastewater treatment efficiencies and sludge settleability of activated sludge in oxic tanks in the test.

\begin{tabular}{|c|c|c|c|c|c|}
\hline Stage & Parameter & Con & TCS & DCP & THPS \\
\hline $0-30 d^{a}$ & $\begin{array}{l}\text { SVI }(\mathrm{mL} / \mathrm{g} \mathrm{SS}) \\
\text { COD removal (\%) } \\
\mathrm{NH}_{4}^{+}-\mathrm{N} \text { removal (\%) } \\
\mathrm{TN} \text { removal (\%) } \\
\mathrm{TP} \text { removal }(\%) \\
\text { Excess sludge reduction }(\%)\end{array}$ & $\begin{array}{l}81.4 \pm 3.6 \\
88.9 \pm 2.1 \\
98.9 \pm 0.3 \\
67.9 \pm 1.7 \\
58.9 \pm 0.8 \\
-\end{array}$ & $\begin{array}{l}82.4 \pm 4.5 \\
85.9 \pm 3.4 \\
97.6 \pm 0.6 \\
59.2 \pm 1.4 \\
56.1 \pm 1.8 \\
38.7 \pm 1.7\end{array}$ & $\begin{array}{l}80.1 \pm 3.9 \\
86.0 \pm 2.6 \\
93.2 \pm 0.4 \\
58.8 \pm 2.6 \\
55.9 \pm 2.3 \\
45.4 \pm 1.9\end{array}$ & $\begin{array}{l}83.8 \pm 2.1 \\
85.7 \pm 1.8 \\
95.6 \pm 1.4 \\
60.2 \pm 2.2 \\
55.8 \pm 3.5 \\
38.3 \pm 0.9\end{array}$ \\
\hline $31-85 d^{b}$ & $\begin{array}{l}\mathrm{SVI}(\mathrm{mL} / \mathrm{g} \mathrm{SS}) \\
\mathrm{COD} \text { removal (\%) } \\
\mathrm{NH}_{4}^{+}-\mathrm{N} \text { removal (\%) } \\
\mathrm{TN} \text { removal (\%) } \\
\text { TP removal (\%) } \\
\text { Excess sludge reduction (\%) }\end{array}$ & $\begin{array}{l}88.0 \pm 2.4 \\
91.1 \pm 2.8 \\
98.7 \pm 0.4 \\
70.4 \pm 2.2 \\
57.2 \pm 1.6 \\
-\end{array}$ & $\begin{array}{l}149.5 \pm 3.8 \\
86.6 \pm 0.6 \\
98.4 \pm 1.4 \\
61.4 \pm 2.8 \\
53.8 \pm 1.9 \\
38.6 \pm 2.4\end{array}$ & $\begin{array}{l}150.2 \pm 0.5 \\
86.0 \pm 3.1 \\
97.8 \pm 0.8 \\
60.6 \pm 3.5 \\
53.7 \pm 1.1 \\
43.4 \pm 1.6\end{array}$ & $\begin{array}{l}158.9 \pm 4.3 \\
87.2 \pm 3.3 \\
98.1 \pm 0.7 \\
61.5 \pm 1.7 \\
53.7 \pm 2.7 \\
39.3 \pm 3.6\end{array}$ \\
\hline
\end{tabular}

a 7 samples.

b 18 samples.
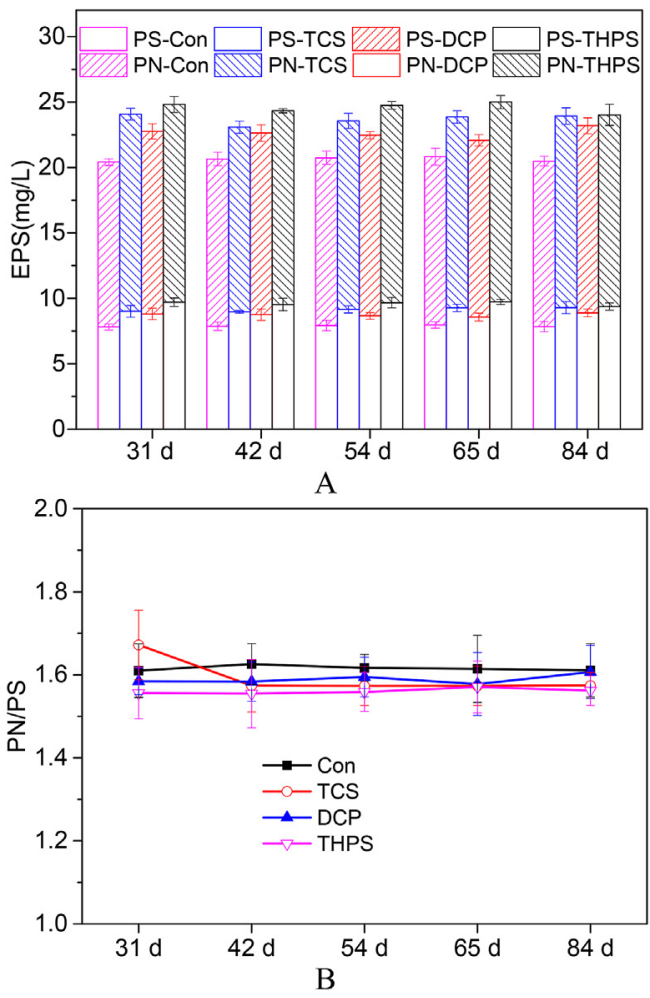

Fig. 1. Variations in EPS content and its PN/PS of activated sludge during the test.

MUs and adapt to in the environment (Henriques and Love, 2007; Feng et al., 2014). Thus, it is reasonable that the addition of MUs increased the PN and PS contents of the activated sludge EPS. Additionally, the effects of different MUs were different. The EPS of activated sludge in THPS system was the highest followed by TCS system (Fig. 1-A).

The PN/PS of EPS was calculated and the results were summarized in Fig. 1-B. The PN/PSs of EPS for activated sludge in four systems were changed in 1.61-1.63 (control system), 1.57-1.67 (TCS system), 1.58-1.61 (DCP system) and 1.55-1.57 (THPS system). The PN/PSs of EPS for activated sludge in control system were higher than those in the three MUs systems except on day 31. The results suggested the PN/PS of activated sludge EPS decreased with the addition of MUs (Fig. 1-B), which indicated more PS than PN was generated in the EPS of the activated sludge in the MUs systems. The addition of THPS decreased most PN/PS of activated sludge followed by the treatment of DCP addition.
The above results suggested the addition of the three MUs led to the increase of activated sludge EPS and the decrease of its PN/PS. The increase in EPS further increases the sludge SVI and deterioration of sludge settleability (Sheng et al., 2010) because activated sludge flocs consist of microbial colonies embedded in a cloud of EPS (Wilén et al., 2008). Meanwhile, the decrease of PN/PS would inhibit the formation of floc by increasing cell surface charges or by decreasing hydrophobicity of sludge cells (Basuvaraj et al., 2015), which would further result in the increase of sludge SVI and the deterioration of sludge settleability (Zita and Hermansson, 1997). The significant correlations analysis suggested the SVI of activated sludge significantly correlated with the EPS content at the 0.01 level, and significantly correlated with the PN/PS of the EPS at the 0.05 level (Table 3). However, the order of activated sludge EPS content in the three MUs system was inconsistent with that of the activated sludge SVI, which suggested that other reasons may also account for the sludge settleability deterioration in MUs systems.

\subsection{AHL content, microbial attachment potential and average particle size of activated sludge}

AHL, an intercellular QS signal molecule in Gram-negative bacteria, affects the microbial community composition and function of activated sludge (Chong et al., 2012). The relative AHL contents of the activated sludge in second stage (31-85 d) were measured and they changed in 1.63-1.84-fold (control system), 1.32-1.39-fold (TCS system), $1.26-1.38$-fold (DCP system) and 1.13-1.25-fold (THPS system) (Fig. 2). The results indicated the relative AHL contents of the activated sludge in control system were the highest and those in the THPS system were the lowest, and the addition of the three MUs decreased the AHL content of activated sludge. Jiang and Liu (2012) also found that TCS decreased the AHL content of aerobic granules. Meanwhile, the relative AHL content of activated sludge in this study was similar to that in previous studies (Lv et al., 2014; Hao et al., 2016). In other words, the three MUs could be looked as QS inhibitors and their addition as quorum quenching (Kalia, 2013). Because AHL could affect the properties and function of activated sludge (Valle et al., 2004; Shrout and Nerenberg, 2012) and better sludge settleability was observed with quorum quenching (Jiang et al., 2013), the decrease of AHL content of activated sludge in the three MUs systems may be one reason for the increase of sludge SVI and deterioration of sludge settleability.

Because the sludge microorganisms assemble in the activated sludge floc and the microbial attachment potential is crucial in the development and formation of the activated sludge floc ( $\mathrm{Lv}$ et al., 2014; Ju and Zhang, 2015), the microbial attachment potentials of 
Table 3

Correlation coefficient of characteristics of activated sludge.

\begin{tabular}{|c|c|c|c|c|c|c|}
\hline Item & SVI & EPS & PN/PS & Relative AHL content & Average size & Microbial attachment potential \\
\hline SVI & 1 & & & & & \\
\hline EPS & $0.705^{* *}$ & 1 & & & & \\
\hline PN/PS & $0.556^{*}$ & $0.81^{* *}$ & 1 & & & \\
\hline relative $\mathrm{AHL}$ content & $0.779^{* *}$ & $0.917^{* *}$ & $0.722^{* *}$ & 1 & & \\
\hline average size & $0.623^{* *}$ & $0.816^{* *}$ & $0.588^{* *}$ & $0.926^{* *}$ & 1 & \\
\hline Microbial attachment potential & $0.658^{* *}$ & $0.806^{* *}$ & $0.557^{* *}$ & $0.935^{* *}$ & $0.891^{* *}$ & 1 \\
\hline
\end{tabular}

* Correlation is significant at the 0.05 level (2-tailed).

${ }^{* *}$ Correlation is significant at the 0.01 level (2-tailed).

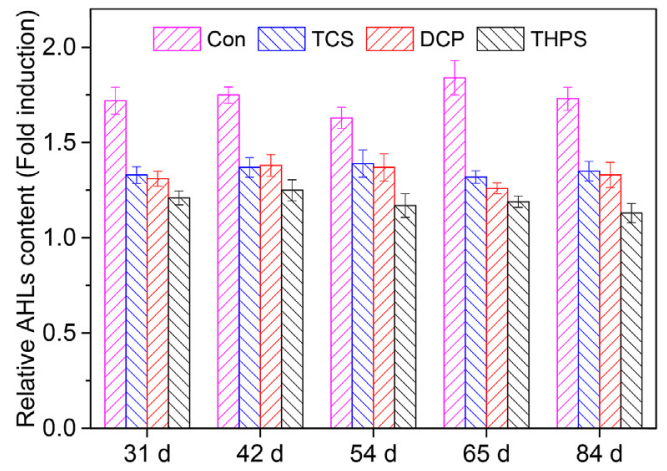

Fig. 2. Variations in relative AHLs content of activated sludge during the test.

activated sludge in four systems were measured (Fig. 3). The microbial attachment potentials of activated sludge in the four systems ranged from $30 \mu \mathrm{g} \mathrm{COD} / \mathrm{cm}^{2}$ to $59 \mu \mathrm{g} \mathrm{COD} / \mathrm{cm}^{2}$, with average values of $53.4 \mu \mathrm{g} \mathrm{COD} / \mathrm{cm}^{2}$ (control system), $44.0 \mu \mathrm{g} \mathrm{COD} / \mathrm{cm}^{2}$ (TCS system), $41.8 \mu \mathrm{g} \mathrm{COD} / \mathrm{cm}^{2}$ (DCP system), and $33.8 \mu \mathrm{g} \mathrm{COD} / \mathrm{cm}^{2}$ (THPS system) (Fig. 3). Fig. 3 showed the microbial attachment potential of activated sludge in the control system was highest and that in the THPS system was the lowest. The results indicated the addition of MUs decreased the microbial attachment potential of activated sludge. Since microbial attachment was believed to play an important role in the stability of activated sludge (Hao et al., 2016), the decrease of microbial attachment potential of activated sludge in the three MUs system may be a reason for the sludge settleability deterioration. Additionally, AHL content of activated sludge was closely relevant to its microbial attachment (Lv et al., 2014; Hao et al., 2016).

The average particle size of the activated sludge was different among the four systems (Fig. 4), and decreased with the addition of the MUs. The average particle sizes in the second stage were $108.94 \mu \mathrm{m}$ (control system), $98.66 \mu \mathrm{m}$ (TCS system), $93.66 \mu \mathrm{m}$ (DCP system), and $88.43 \mu \mathrm{m}$ (THPS system). The average particle size of

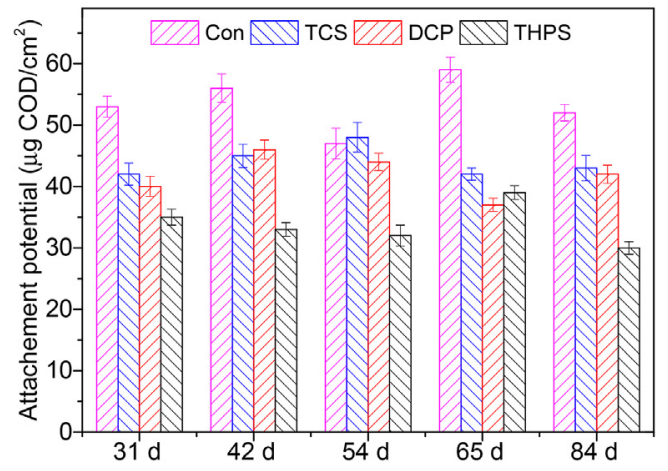

Fig. 3. Variations in attachment potential of activated sludge during the test.

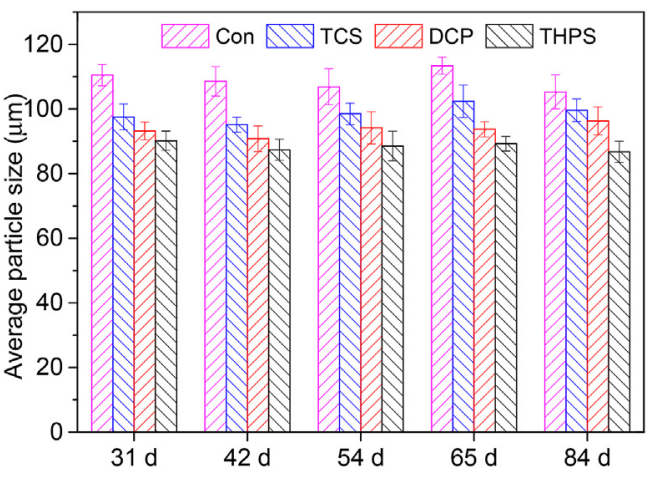

Fig. 4. Variations in average size of activated sludge during the test.

the sludge was the least in the THPS system, followed by the DCP system. Because particle size of activated sludge may affect its settleability and lower SVI was observed with decreasing sludge size (Andreadakis, 1993), the decrease of activated sludge particle size induced by MUs may also be a reason for the sludge settleability deterioration.

To determine the correlation among the above three parameters and SVI of the activated sludge, a Pearson correlation was used (Table 3). The results showed the SVI of the activated sludge significantly correlated with the three parameters at the 0.01 level. Additionally, the AHL content of the activated sludge significantly correlated with the average size and microbial attachment potential at the 0.01 level. The results showed the addition of MUs decreased the AHL content of activated sludge, which further reduced the microbial attachment potential (Lv et al., 2014) and decreased the average particle size of the activated sludge, and inhibited the formation of floc structures. The decreased microbial attachment potential and average particle size may eventually increase the SVI of sludge and deteriorate the sludge settleability (Ju and Zhang, 2015). Meanwhile, the coefficient of correlation (R) between the sludge SVI and the relative AHL content was the highest $(R=0.779)$ in those between it and other parameters (Table 3), which suggested that the correlation between the sludge SVI and the relative AHL content was also the highest. Thus, the decreased AHL content of activated sludge may be the key reason for the deterioration of sludge settleability in sludge reduction systems with MUs.

\subsection{Microbial population of activated sludge}

The microbial population of the activated sludge in the four systems, as sampled in the second stage ( $70^{\text {th }}$ day), was analyzed by molecular biological methods, as shown in Fig. 5. The DGGE profile displayed bands in the MUs systems at 50.5\% (TCS system), 51.6\% (DCP system), and 50.9\% (THPS system), whereas the bands in the control system were low. These results suggested that the microbial population of the activated sludge in the control system was very 

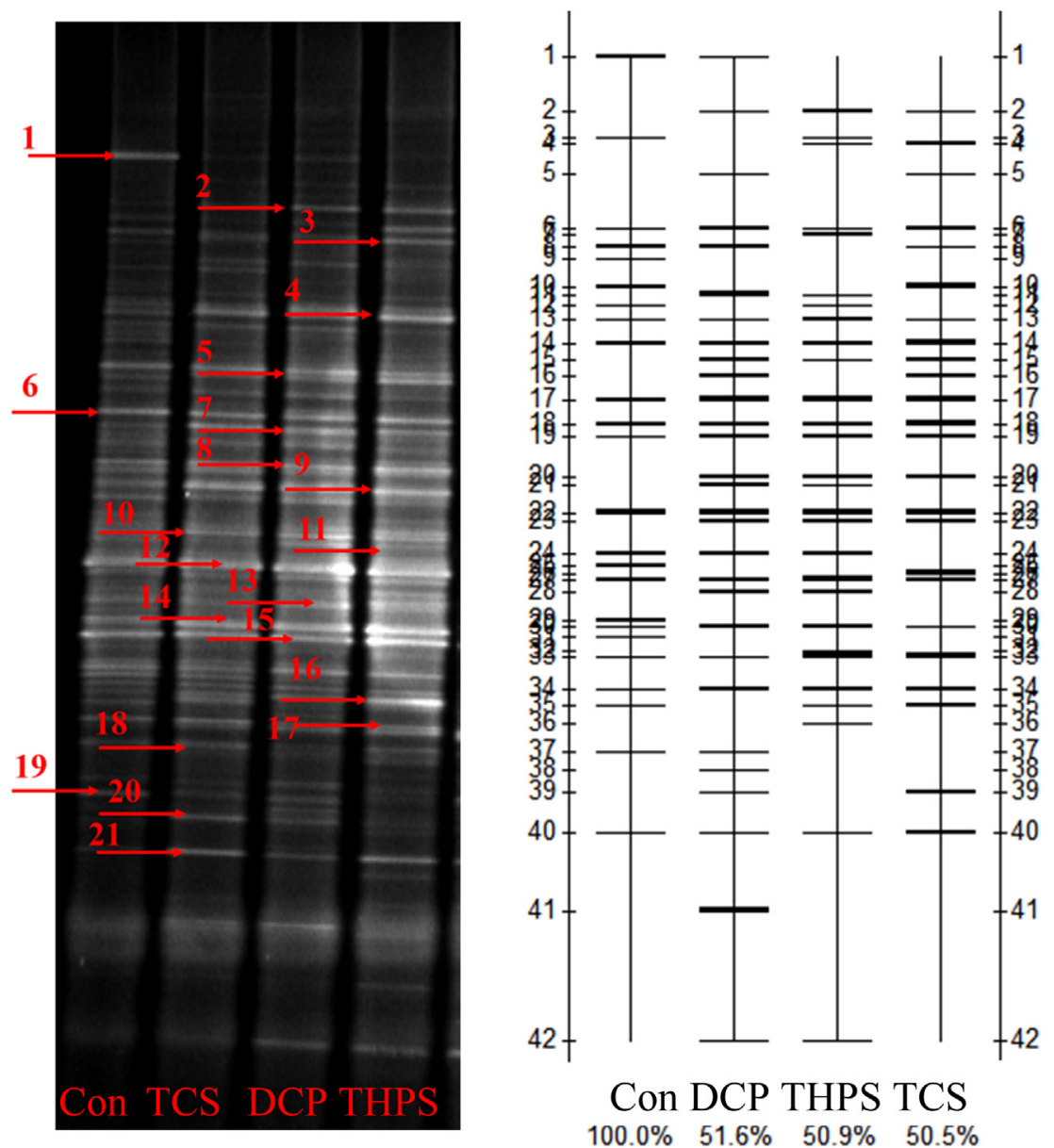

Fig. 5. DGGE profiles for sludge samples in four systems.

different from those in the MUs systems, but was similar among the three MUs systems.

The dominant bands were excised from the DGGE gel and sequenced, and the sequences were compared with those available from the GenBank database, using BLASTN (Table 4). All sequences were $98 \%-100 \%$ homologous with previously identified 16S rRNA gene sequences, with the bacteria belonging to Zoogloea sp. (band 1), Paenibacillus sp. (bands 2, 6,12,15,18), Bacillus sp. (bands 3, 7,10, 11 and 21), Pedobacter sp. (band 4), Chloroflexi sp. (bands 5 and 20), Microbacterium sp. (bands 8 and 17), Pseudomonas sp. (band 9), Planococcaceae sp. (band 13), Gamma proteobacterium (band 14), Brevibacillus sp. (band16), and Paracoccus sp. (band 19). As shown in Fig. 5 and Table 4, Zoogloea sp., Microbacterium sp., and Paracoccus sp. detected in the controls were not detected in the second stage of the MUs systems, whereas Microbacterium sp., Bacillus sp., and Chloroflexi sp. were only found in the MUs systems. Otherwise, the content of some bacteria, as represented by bands $3,4,7,8,12,13$, 14,15 , and 16 , increased in the MUs systems. Above results suggested that the addition of MUs affected the microbial population of activated sludge. Previous studies reported similar results (Ye and Li, 2005; Tian et al., 2013; Kimura et al., 2016). Tian et al. (2013) found that 2,6-DCP was much more toxic to autotrophic microorganisms than heterotrophic microorganisms. Kimura et al. (2016) found that the DGGE patterns of the 3,5-DCP-added system were different from those of the control system.

With regard to the microbial population of activated sludge in this study, Zoogloea sp., Bacillus sp., Pedobacter sp., Chloroflexi sp., and Pseudomonas sp. (Table 4), were microorganisms commonly

Table 4

Sequence identities and characteristics of bacterial clones that appeared in Fig. 5.

\begin{tabular}{|c|c|c|c|c|c|}
\hline Band & Closest relatives & Similarity & Band & Closest relatives & Similarity \\
\hline 1 & uncultured Zoogloea sp. & $100 \%$ & 12 & Paenibacillus ourofinensis & $99 \%$ \\
\hline 2 & Microbacterium sp. MCCC 1A10728 & $100 \%$ & 13 & Planococcaceae bacterium Bac135R & $99 \%$ \\
\hline 3 & Bacillus sp. PnB 5 & $100 \%$ & 14 & uncultured gamma proteobacterium & $98 \%$ \\
\hline 4 & uncultured Pedobacter sp. & $100 \%$ & 15 & Paenibacillus elgii & $99 \%$ \\
\hline 5 & uncultured Chloroflexi bacterium & $98 \%$ & 16 & Brevibacillus reuszeri & $99 \%$ \\
\hline 6 & Lachnospiraceae bacterium MC-35 & $100 \%$ & 17 & Microbacterium sp. MCCC 1A10728 & $100 \%$ \\
\hline 7 & Bacillus oceanisediminis & $100 \%$ & 18 & & \\
\hline 8 & Microbacterium sp. MCCC 1A10728 & $100 \%$ & 19 & Paracoccus solventivorans & $99 \%$ \\
\hline 9 & uncultured Pseudomonas sp. & $99 \%$ & 20 & uncultured Chloroflexi bacterium & $98 \%$ \\
\hline 10 & uncultured Burkholderiales bacterium & $99 \%$ & 21 & Bacillus sp. PnB 5 & $100 \%$ \\
\hline 11 & Bacillus oceanisediminis & $100 \%$ & & & \\
\hline
\end{tabular}


observed in the activated sludge (Gonzalez-Martinez et al., 2016). Previous studies showed Pseudomonas sp. (band 9) and Paracoccus sp. (band 19) were AHL-producing bacteria (Morgan-Sagastume et al., 2005; Ochiai et al., 2013; Waheed et al., 2016), whereas Microbacterium spp. (bands 8 and 17) and Paenibacillus spp. (bands 2, 6, 12, 15, and 18) were AHL-degrading bacteria (Kim et al., 2014). Thus, the decrease or disappearance in Paracoccus sp. (band 19) and the increase or appearance in Microbacterium sp. (band 8) and Paenibacillus sp. (bands 2,12, and 15) (Fig. 5) may be the reasons for the decrease of relative AHL content in the MUs systems. In addition, the increase in Paenibacillus sp. (bands 2,12, and 15) resulted in the deterioration of sludge settleability, because Paenibacillus sp. reportedly leads to poor sludge settling (Simpson et al., 2006) and is responsible for non-filamentous sludge bulking (Iyer and Oerther, 2003). In other words, the addition of MUs changed the microbial population of activated sludge, which further resulted in the decrease of relative AHL content and the deterioration of sludge settleability.

\section{Conclusions}

The SVI of the activated sludge increased from $88.0 \mathrm{~mL} / \mathrm{g}$ SS to 149.5-158.9 $\mathrm{mL} / \mathrm{g} \mathrm{SS}$, showing that the addition of MUs deteriorated the sludge settleability. The addition of MUs changed the microbial communities and EPS of the sludge, which were factors for sludge settleability deterioration. The changes of microbial communities decreased the AHL content of sludge in the MUs systems, which further decreased the microbial attachment potential and average particle sizes of sludge, and inhibited the formation of floc. The changes in microbial population and the decrease of AHL content may be the key reasons for the sludge settleability deterioration.

\section{Acknowledgements}

We gratefully acknowledge the financial support from the National Natural Science Foundation of China (Nos. 51378492, 51308068 and 51308527). Additionally, we thank LetPub (www. letpub.com) for its linguistic assistance during the preparation of this manuscript.

\section{References}

American Public Health Association (APHA), 1998. Standard Methods for the Examination of Water and Wastewater, twentieth ed. American Public Health Association, Washington DC, USA.

Andreadakis, A.D., 1993. Physical and chemical properties of activated sludge floc. Water Res. 27, 1707-1714.

Basuvaraj, M., Fein, J., Liss, S.N., 2015. Protein and polysaccharide content of tightly and loosely bound extracellular polymeric substances and the development of a granular activated sludge floc. Water Res. 82, 104-117.

Campos, J.L., Otero, L., Franco, A., Mosquera-Corral, A., Roca, E., 2009. Ozonation strategies to reduce sludge production of a seafood industry WWTP. Bioresour. Technol. 100, 1069-1073.

Chong, G., Kimyon, O., Rice, S.A., Kjelleberg, S., Manefield, M., 2012. The presence and role of bacterial quorum sensing in activated sludge. Microb. Biotechnol. 5, 621-633.

Dubois, M., Gilles, K.A., Hamilton, J.K., Rebers, P.A., Smith, F., 1956. Colorimetric method for determination of sugars and related substances. Anal. Chem. 28, $350-356$.

Fang, F., Hu, H.-L., Qin, M.-M., Xue, Z.-X., Cao, J.-S., Hu, Z.-R., 2015. Effects of metabolic uncoupler on excess sludge reduction and microbial products of activated sludge. Bioresour. Technol. 185, 1-6.

Feng, X.-C., Guo, W.-Q., Yang, S.-S., Zheng, H.-S., Du, J.-S., Wu, Q.-L., Ren, N.-Q., 2014 Possible causes of excess sludge reduction adding metabolic uncoupler 3,3', 4',5-tetrachlorosalicylanilide (TCS), in sequence batch reactors. Bioresour. Technol. 173, 96-103.

Gonzalez-Martinez, A., Rodriguez-Sanchez, A., Lotti, T., Garcia-Ruiz, M.-J., Osorio, F., Gonzalez-Lopez, J., van Loosdrecht, M.C.M., 2016. Comparison of bacterial communities of conventional and A-stage activated sludge systems. Sci. Rep. 6, 18786.
Guo, W.Q., Yang, S.-S., Xiang, W.-S., Wang, X.-J., Ren, N.-Q., 2013. Minimization of excess sludge production by in-situ activated sludge treatment processes - a comprehensive review. Biotechnol. Adv. 31, 1386-1396.

Guo, X., Yang, J., Liang, Y., Liu, J., Xiao, B., 2014. Evaluation of sludge reduction by an environmentally friendly chemical uncoupler in a pilot-scale anaerobic-anoxicoxic process. Bioproc. Biosyst. Eng. 37, 553-560.

Han, Y., Sun, Y., Chen, H., Guo, X., Yu, C., Li, Y., Liu, J., Xiao, B., 2017. Effects of wastewater treatment processes on the sludge reduction system with 2,4 dichlorophenol: sequencing batch reactor and anaerobic-anoxic-oxic process. J. Biotech. 251, 99-105.

Hao, W., Lv, J., Li, Y., Chen, L., Zhu, J., 2016. The effect of metal ions on the microbial attachment ability of flocculent activate sludge. Environ. Technol. 37, 722-731.

Henriques, I.D.S., Love, N.G., 2007. The role of extracellular polymeric substances in the toxicity response of activated sludge bacteria to chemical toxins. Water Res. 41, 4177-4185.

Huang, J., Shi, Y., Zeng, G., Gu, Y., Chen, G., Shi, L., Hu, Y., Tang, B., Zhou, J.X., 2016. Acyl-homoserine lactone-based quorum sensing and quorum quenching hold promise to determine the performance of biological wastewater treatments: an overview. Chemosphere 157, 137-151.

Iyer, N., Oerther, D.B., 2003. Paenibacillus spp. and sludge bulking. Water Environment Federation. In: Proceedings of Research Symposium. WEFTEC, Los Angeles, CA. October 11-October 15.

Jiang, B., Liu, Y., 2012. Roles of ATP-dependent N-acylhomoserine lactones (AHLs) and extracellular polymeric substances (EPSs) in aerobic granulation. Chemosphere 88, 1058-1064.

Jiang, W., Xia, S., Liang, J., Zhang, Z., Hermanowicz, S.W., 2013. Effect of quorum quenching on the reactor performance, biofouling and biomass characteristics in membrane bioreactors. Water Res. 47, 187-196.

Ju, F., Zhang, T., 2015. Bacterial assembly and temporal dynamics in activated sludge of a full-scale municipal wastewater treatment plant. ISME J. 9, 683-695.

Kalia, V.C., 2013. Quorum sensing inhibitors: an overview. Biotechnol. Adv. 31, $224-245$.

Kim, A.-L., Park, S.-Y., Lee, C.-H., Lee, C.-H., Lee, J.-K., 2014. Quorum quenching bacteria isolated from the sludge of a wastewater treatment plant and their application for controlling biofilm formation. J. Microbiol. Biotechnol. 24, 1574-1582.

Kimura, Z., Hirano, Y., Matsuzawa, Y., Hiraishi, A., 2016. Effects of 3,5-dichlorophenol on excess biomass reduction and bacterial community dynamics in activated sludge as revealed by a polyphasic approach. J. Biosci. Bioeng. 122, 467-474.

Li, P., Li, H., Li, J., Guo, X., Liu, J., Xiao, B., 2016. Evaluation of sludge reduction of three metabolic uncouplers in laboratory-scale anaerobic-anoxic-oxic process. Bioresour. Technol. 221, 31-36.

Liu, Y., Fang, H.H.P., 2002. Extraction of extracellular polymeric substances (EPS) of sludges. J. Biotechnol. 110, 1107-1117.

Lowry, O.H., Rosebrough, N.J., Farr, A.L., Randall, R.J., 1951. Protein measurement with the Folin phenol reagent. J. Biol. Chem. 1993, 265-275.

Lv, J., Wang, Y., Zhong, C., Li, Y., Hao, W., Zhu, J., 2014. The microbial attachment potential and quorum sensing measurement of aerobic granular activated sludge and flocculent activated sludge. Bioresour. Technol. 151, 291-296.

Morgan-Sagastume, F., Boon, N., Dobbelaere, S., Defoirdt, T., Verstraete, W., 2005 Production of acylated homoserine lactones by Aeromonas and Pseudomonas strains isolated from municipal activated sludge. Can. J. Microbiol. 51, 924-933.

Ochiai, S., Morohoshi, T., Kurabeishi, A., Shinozaki, M., Fujita, H., Sawada, I., Ikeda, T., 2013. Production and degradation of $\mathrm{N}$-acyhomoserine lactone quorum sensing signal molecules in bacteria isolated from activated sludge. Biosci. Biotechnol. Biochem. 77, 2436-2440.

Ou, H.S., Wei, C.H., Mo, C.H., Wu, H.Z., Ren, Y., Feng, C.H., 2014. Novel insights into anoxic/aerobic ${ }^{1} /$ aerobic $^{2}$ biological fluidized-bed system for coke wastewater treatment by fluorescence excitation-emission matrix spectra coupled with parallel factor analysis. Chemosphere 113, 158-164.

Semblante, G.U., Hai, F.I., Bustamante, H., Guevara, N., Price, W.E., Nghiem, L.D., 2015. Effects of iron salt addition on biosolids reduction by oxic-settling-anoxic (OSA) process. Int. Biodeterior. Biodegrad. 104, 391-400.

Sheng, G.P., Yu, H.Q., Li, X.Y., 2010. Extracellular polymeric substances (EPS) of microbial aggregates in biological wastewater treatment systems: a review. Biotechnol. Adv. 28, 882-894.

Shrout, J.D., Nerenberg, R., 2012. Monitoring bacterial twitter: does quorum sensing determine the behavior of water and wastewater treatment biofilms? Environ. Sci. Technol. 46, 1995-2005.

Simpson, J.M., Stroot, P.G., Butler, R., Gelman, S., Beydilli, I., Dudley, S., Oerther, D.B. 2006. 16S rRNA tools demonstrate an unexpected predominance of Paenibacillus-like bacteria in an industrial activated sludge system. Water Environ. Res. 78, 864-871.

Solano, C., Echeverz, M., Lasa, I., 2014. Biofilm dispersion and quorum sensing. Curr. Opin. Microbiol. 18, 96-104.

Sperling, M.V., 2007. Basic Principle of Wastewater Treatment. IWA Publishing.

Sun, Y., He, K., Yin, Q., Echigo, S., Wu, G., Guan, Y., 2017. Determination of quorumsensing signal substances in water and solid phases of activated sludge systems using liquid chromatography-mass spectrometry. J. Environ. Sci. China. http:// doi.org/10. 1016/j. jes.2017.04.017.

Tian, Y., Zhang, Y., Wu, D., 2013. Distribution variation of a metabolic uncoupler, 2,6dichlorophenol (2,6-DCP) in long-term sludge culture and their effects on sludge reduction and biological inhibition. Water Res. 47, 279-288.

Valle, A., Bailey, M.J., Whiteley, A.S., Manefield, M., 2004. N-acyl-L-homoserine lactones (AHLs) affect microbial community composition and function in 
activated sludge. Environ. Microbio. 6, 424-433.

Waheed, H., Hashmi, I., Khan, S.J., Kim, S.R., Arshad, M., Nasir, H., 2016. Microbia population dynamics and profiling of quorum sensing agents in membrane bioreactor. Int. Biodeterior. Biodegrad. 113, 66-73.

Wilén, B.-M., Lumley, D., Mattsson, A., Mino, T., 2008. Relationship between floc composition and flocculation and settling properties studied at a full scale activated sludge plant. Water Res. 42, 4404-4418.

Wu, L., Li, A., Hou, B., Li, M., 2017. Exogenous addition of cellular extract N-acylhomoserine-lactones accelerated the granulation of autotrophic nitrifying sludge. Int. Biodeterior. Biodegrad. 118, 119-125.

Xie, W.M., Ni, B.J., Sheng, G.P., Yu, H.Q., Yang, M., 2010. Substrate consumption and excess sludge reduction of activated sludge in the presence of uncouplers: modeling approach. Appl. Microbiol. Biotechnol. 85, 2001-2008.

Ye, F.X., Li, Y., 2005. Reduction of excess sludge production by $3,3^{\prime}, 4^{\prime}, 5-$ tetrachlorosalicylanilide in an activated sludge process. Appl. Microbiol. Biotechnol. 67, 269-274.

Zheng, G.H., Li, M.N., Wang, L., Chen, Z.Y., Qian, Y.F., Zhou, Q., 2008. Feasibility of 2,4,6-trichlorophenol and malonic acid as metabolic uncoupler for sludge reduction in the sequence batch reactor for treating organic wastewater. Appl. Biochem. Biotechnol. 144, 101-109.

Zita, A., Hermansson, M., 1997. Effects of bacterial cell surface structures and hydrophobicity on attachment to activated sludge flocs. Appl. Environ. Microbio. 63, 1168-1170. 